\title{
Questions of importance to the conservation of biological diversity: answers from the past
}

\author{
K. J. Willis ${ }^{1,3,4}$ and S. A. Bhagwat ${ }^{1,2,3}$ \\ ${ }^{1}$ Long-term Ecology Laboratory, Department of Zoology, University of Oxford, Oxford OX1 3PS, UK \\ ${ }^{2}$ School of Geography and the Environment, University of Oxford, Oxford OX1 3QY, UK \\ ${ }^{3}$ Institute of Biodiversity, Oxford Martin School, University of Oxford, Oxford OX1 3PS, UK \\ ${ }^{4}$ Department of Biology, University of Bergen, P.O. Box 7803, 5020 Bergen, Norway
}

Received: 12 May 2010 - Published in Clim. Past Discuss.: 10 June 2010

Revised: 13 October 2010 - Accepted: 25 October 2010 - Published: 18 November 2010

\begin{abstract}
Paleoecological records are replete with examples of biotic responses to past climate change and human impact, but how can we use these records in the conservation of current and future biodiversity? A recently published list of (One Hundred Questions of Importance to the Conservation of Global Biological Diversity) (Sutherland et al., 2009) highlights a number of key research questions that need a temporal perspective. Many of these questions are related to the determination of ecological processes in order to assess ecosystem function and services, climate changeintegrated conservation strategies, and ecosystem management and restoration. However, it is noticeable that not a single contributor to this list was from the paleo-research community and that extremely few paleo-records are ever used in the development of terrestrial conservation management plans. This lack of dialogue between conservationists and the paleo-community is partially driven by a perception that the data provided by paleoecological records are purely descriptive and not of relevance to the day-to-day management and conservation of biological diversity. This paper illustrates, through a series of case-studies, how long-term ecological records ( $>50$ years) can provide a test of predictions and assumptions of ecological processes that are directly relevant to management strategies necessary to retain biological diversity in a changing climate. This discussion paper includes information on diversity baselines, thresholds, resilience, and restoration of ecological processes.
\end{abstract}

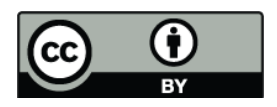

Correspondence to: $\mathrm{K}$. J. Willis (kathy.willis@ouce.ox.ac.uk)

\section{Introduction}

The United Nations Convention on Biological Diversity entered into force in 1993 and set the scene for conservation of the variety of life on Earth including genes, species and ecosystems. A number of international conservation organizations subsequently devised strategies to identify and protect global biological diversity. These include, for example, Birdlife International's Important Bird Areas (Brown et al., 1995), WWF's ecoregions (Olson and Dinerstein, 1998), and Conservation International's Biodiversity Hotspots (Myers et al., 2000). In 2002, the Parties to the Convention committed themselves "to achieve by 2010 a significant reduction of the current rate of biodiversity loss at the global, regional and national level as a contribution to poverty alleviation and to the benefit of all life on Earth" (CBD, 2010). The international conservation strategies established in the 1990s and implemented subsequently have been at the forefront of achieving this target. These strategies use quantitative methods to identify priority areas for conservation and aim to determine the most important regions based on measure(s) of a combination of different factors including species richness, endemism, threat and uniqueness. Such methods have resulted in the current prioritization of approximately $12 \%$ of the Earth's terrestrial surface for protection at local, regional or global scales (Jenkins and Joppa, 2009). However, once an area has been prioritised for conservation, what methods are needed to conserve biological diversity in the region?

It has long been argued that in order to conserve biodiversity in a changing world, conservation planners must incorporate an understanding of the dynamic processes of species and their interactions with their environment into conservation planning (Mace et al., 1998; Pressey et al., 2007; Mace

Published by Copernicus Publications on behalf of the European Geosciences Union. 
and Purvis, 2008). With the increasing threats of climate change and human impact (e.g., Marlon et al., 2008), most conservation organisations now acknowledge the relevance of ecological processes to conservation. These include, for example, stated aims to create ecological conditions necessary for resilience, persistence and the prevention of thresholds and irreversible changes in ecosystems. Ecological processes include climatic processes, primary productivity, hydrological processes, formation of biophysical habitats, interactions between species, movements of organisms and natural disturbance regimes, all of which influence biological diversity (Bennett et al., 2009). What is still lacking, however, is an understanding of how to identify the ecological processes important to achieving these aims, and then how to devise policies to conserve them. This underlies one of the main problems with planning for dynamic ecosystems; it is often far from obvious what data should be used to determine ecological processes, and what ecological processes should be conserved.

Within conservation biology there is a tendency to examine ecological processes at the ecological timescale, with datasets spanning at most up to 50 years, but more often between 1-5 years. However, many of the ecological processes that are relevant to understanding patterns of biological diversity occur over longer timescales spanning $10 \mathrm{~s}-1000 \mathrm{~s}$ years. Furthermore, to understand evolutionary processes, this timescale must be even longer. The tendency, therefore, has been to either extrapolate from short-term records or to rely heavily upon models to determine ecological process. Although these methods can provide a first-order approximation, they can also lead to some misguided predictions and assumptions, sometimes leading to inappropriate policy and management decisions.

An additional method for determination of ecological processes, and one that is currently under-utilized, is the use of longer-term ecological records contained in historical and fossil records (for a review see Willis et al., 2010). Reasons for an absence of long-term ecological temporal datasets in biodiversity assessments and reports are most often driven by a lack of appreciation of the type of data such records can provide (Willis et al., 2007). There is also the perception that climate change and human impact are now so much faster and greater than anything ever experienced before in Earth's history and that we will be experiencing novel ecosystems. Thus it is argued that in many situations, determination of historical restoration targets are not going to be relevant to current and future conservation practices (Hobbs et al., 2006; Jackson and Hobbs, 2009).

This paper asks: what are the most important questions relating to the conservation of biological diversity that can be addressed using long-term ecological methods and datasets? Through a series of case-studies and examples it examines their use in: (i) determining ecological processes important for maintaining target ecosystems; (ii) understanding thresholds and building ecosystem resilience in response to climate change; (iii) restoration of ecological processes in degraded landscapes; and (iv) identification of regions important for conservation of evolutionary processes.

\section{Which ecological processes are important for maintaining target ecosystems?}

Biodiversity base-lines still form the corner-stone of many conservation strategies where the aim is to conserve and/or maintain characteristic features of the protected area such as endemic species, a combination of species, or a particular community assemblage. There are many levels of management strategies that are applied to these protected areas. One such strategy is the IUCN Protected Area Categories (Dudley, 2008) which recognizes seven different levels of management ranging from category $1 \mathrm{a}$, strict nature reserve, managed mainly for science and excluding people, through to a category VI which is managed mainly for the sustainable use of the natural ecosystem and allows harvesting by people to occur within the reserve. Rarely, within this management framework, is consideration given to the processes to be preserved in order to maintain the biodiversity within the reserve (Boitani et al., 2008) or those responsible for the biodiversity in the first place. This was a case in point with the Sierra de Manatlan UNESCO Biosphere reserve (SMBR) (FigueroaRangel et al., 2008) in Western Mexico. The SMBR is a region of tropical humid and temperate grasslands covering approximately $1400 \mathrm{~km}^{2}$ in Western Mexico. Here a number of the major habitat and land-cover types are protected and managed according to the IUCN classification scheme. These include upland pine-dominated forests which are seen as a priority and have been classified as an IUCN core zone 1a; thus an area where people are excluded. However, it is also assumed that these pine-dominated forests are a secondary succession following past anthropogenic activities. The IUCN 1a classification could therefore potentially be at odds with the aim to conserve the ecological processes because the factors responsible for maintaining the target ecosystem (humans) are removed from the system using this management strategy.

A paleoecological sedimentary sequence spanning the last 4200 cal yr BP (before present) was analyzed from a sedimentary site situated in the pine-dominated forest to determine whether this forest type was a human or natural legacy. A second aim was to determine the natural variability of the forests prior to prehistoric human activity and how this altered in response to climate change (Figueroa-Rangel et al., 2008). Results indicated that Pinus was the dominant tree species for the entire length of record and was established in the region long before the presence of humans. This Pinusdominated forest type is not therefore a result of secondary succession following anthropogenic activities. This study also indicated that during an interval of increased humidity between $2500-1260$ cal yr BP cloud forest taxa became 


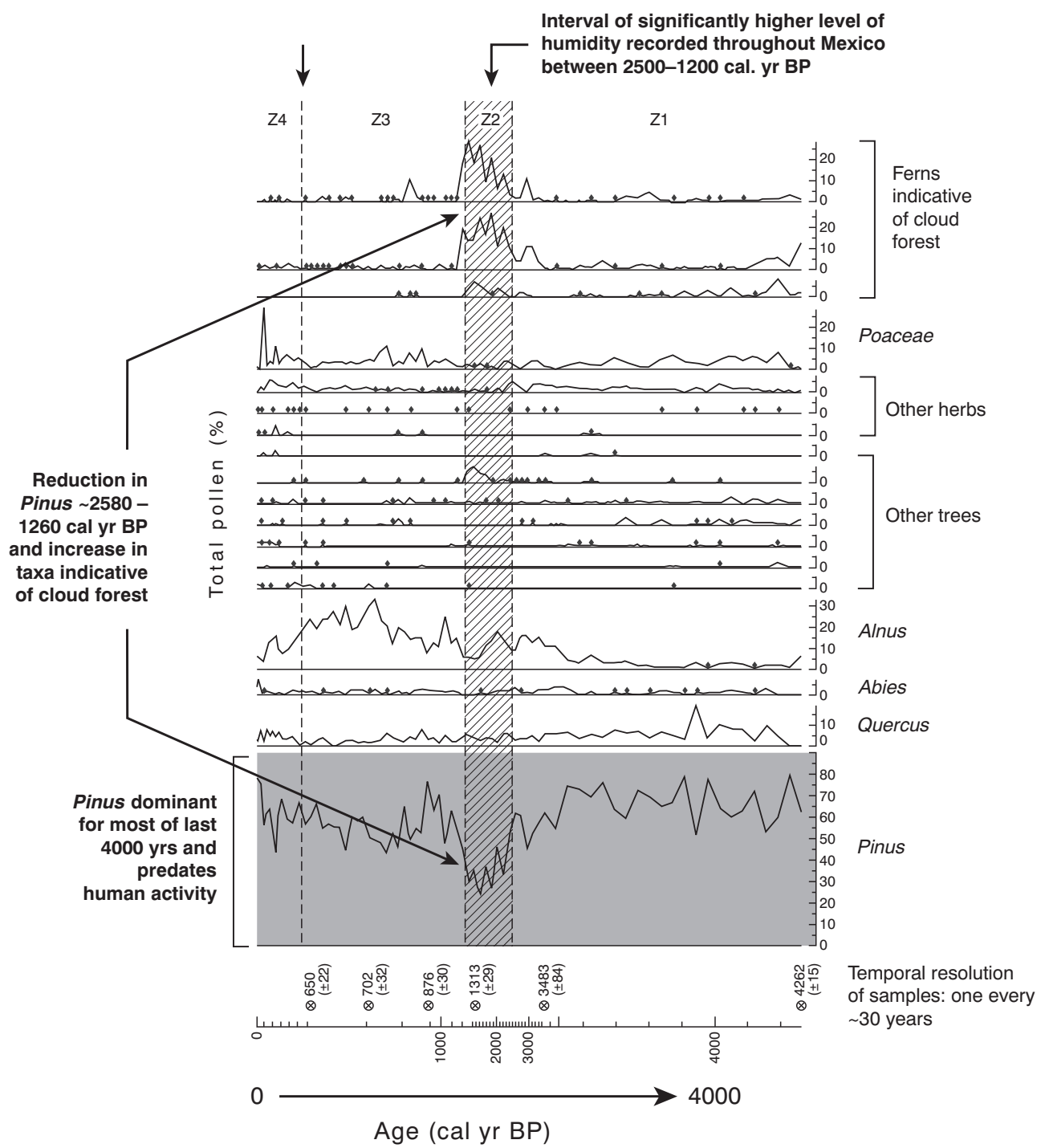

Fig. 1. Percentage pollen diagram of the pine-dominated forest in West-Central Mexico over the past 4200 years for total pollen sum, including spores of ferns. Ages are calibrated years BP (mean and 95\% confidence interval of accuracy) (Redrawn from Figueroa-Rangel et al., 2008).

established in the area and reduced dominance of the Pinus and that this was a natural response to climate change. Natural burning (as recorded in the charcoal record) also indicated a close positive correlation with Pinus, suggesting that in combination with aridity, burning is an important process in maintaining this forest type. Results from this study, therefore, not only indicate the naturally occurring vegetation in this region but also processes responsible for its presence and persistence (aridity and burning). It also suggests that despite people having been present in the region for several thousand years, they had little impact on the existing Pinus dominated forest and suggests that the current management strategy of excluding any anthropogenic activities in this part of the reserve is probably unnecessary (Figueroa-Rangel et al., 2008) (Fig. 1).
This is but one example; there are numerous paleoecological studies from many regions of the world indicating the importance of such data for determination of baselines and processes responsible for the current biodiversity. In the absence of paleoecological records, often basic ecological assumptions are made about the processes responsible for the present-day diversity and general "rules" are often applied uncritically across regions and sometimes even continents. This is particularly true of assumptions related to burning regimes, particularly in grassland ecosystems (see, for example, Foster and Motzkin, 2003; Maxwell, 2004). A number of recent studies have indicated that in regions that climatically should be able to support trees (e.g., S. Africa and Madagascar), there is a tendency to assume that all grasslands are a consequence of previous anthropogenic activity 
(Bond et al., 2008). By the classification of grasslands as "anthropogenic" they often acquire the label of a "degraded" landscape and therefore are of little conservation priority. However, many of these grasslands are in fact without any anthropogenic management, are naturally occurring and contain important endemic species of high conservation priority (e.g., Parr et al., 2002; Bond et al., 2008; Willis et al., 2008; Bond and Parr, 2010).

\section{Determination of thresholds and conserving resilient ecosystems}

Another key question related to current and future biodiversity conservation is how will taxa and the processes they are involved in respond to current and future environmental changes (Willis and Birks, 2006)? In recent years there has been an increasing concern over the prospect of critical thresholds or tipping points when, following a biotic/abiotic environmental change, the ecosystem shifts abruptly from one stable state to another (Folke et al., 2004; Scheffer et al., 2009). A number of conservation organizations now acknowledge critical thresholds as a current and future threat and the need to create conditions that ensure persistence and resilience against threshold events.

Thresholds and tipping points are one area where the utility of longer term records have been recognized for some time within conservation science - particularly in marine systems for both the identification of tipping points (Scheffer et al., 2001) and also regions/communities that appear to be more resilient to threshold events (West and Salm, 2003). There have also been some excellent studies examining the timing and possible driving mechanisms of threshold events in terrestrial ecosystems (e.g., Carrion et al., 2001; Dearing, 2008). To date, the majority of these records have been used to describe the past occurrence of threshold events and demonstrate that mechanisms responsible often involve a combination of biotic and abiotic factors. What is probably more critical to conservation planning, however, is to determine which regions are more resilient to threshold events and the ecological processes that are responsible for this resilience. Such information can then be used in two important ways: first, to prioritize resilient areas in conservation planning, since these regions are likely to be more robust in the face of future climate change (West and Salm, 2003); and second, to try to build resilience into ecosystems, thereby creating conditions that might enable greater persistence in the face of environmental change.

One study that has attempted to identify spatial patterns of resilience and ecological factors responsible using long-term ecological records is for the highly biodiverse coastal ecosystems in south-east Madagascar including littoral forest and Ericaceae-dominated heathland (Virah-Swamy et al., 2008). Vegetation dynamics spanning the past $\sim 4000$ years were reconstructed for four sites along the south-eastern coast us- ing paleoecological techniques including pollen analysis and sediment geochemistry. Abiotic changes occurring over the same interval were also reconstructed, including climatic change and storm surges associated with sea-level rise using a variety of geochemical analyses. This study identified a series of threshold events that occurred over the past 4000 years in response to the combined influence of storm surges (resulting from sea-level rise) and intervals of aridity. A combination of these two abiotic factors resulted in a rapid switch ( $<50$ years) from littoral forest to Ericaceae-dominated heathland at four sites on the coast. The Ericaceae-dominated heathland is thus a naturally occurring vegetation type following environmental peturbations and is not as a result of past human activities. Results from this study also demonstrated, however, that the initial composition of the forest appeared to influence both the resilience and the nature of recovery of the vegetation following the perturbation. Specifically, the diverse littoral forest was more resilient to the triggering mechanisms (sea-level rise and storm surges), showing greater resistance to the initial environmental perturbation and a quicker return to forest following disturbance. In contrast, the open Uapaca woodland appeared to be far less resistant and underwent a threshold event after the first combined storm surge and aridity event. It then never recovered and this region has remained as Ericaceous heathland ever since (Fig. 2).

An initial take-home message for conservation planning from this study is to make conservation of the littoral forest fragments a priority, as well as the naturally occurring heathland mosaic around them because this appears to have provided refugia for species during intervals of aridity and storm surges (Virah-Swamy et al., 2009a,b). However, this study also indicated that some littoral forest fragments seem to provide greater refuge for endemic species than others during environmental perturbations. One example is the Madagascan endemic evergreen forest tree, Symphonia. This is an important genus in Madagascar - many of its species produce nectar and fruits that are consumed by bats, birds and lemurs, but it presently only grows in some fragments of littoral forest and not others (Goodman and Benstead, 2003). On examination of long-term ecological records from two sedimentary sequences at the littoral forest sites, it was apparent that following the climatic perturbations, Symphonia went locally extinct at one site but not at the other. It was also apparent that at both sites there was a close relationship between the abundance of Symphonia and the presence of populations of Erica spp. and Myrica (Fig. 3a).

To determine the reason for this apparent difference between littoral forest fragments, population models were applied to the pollen abundance data to understand whether the local extinction of Symphonia was modulated by competition and/or facilitation (Virah-Swamy et al., 2009b). Four alternative hypotheses were considered: (i) that there was competition between Symphonia and Erica spp., (ii) facilitation by Myrica (which is an important nitrogen fixer in 


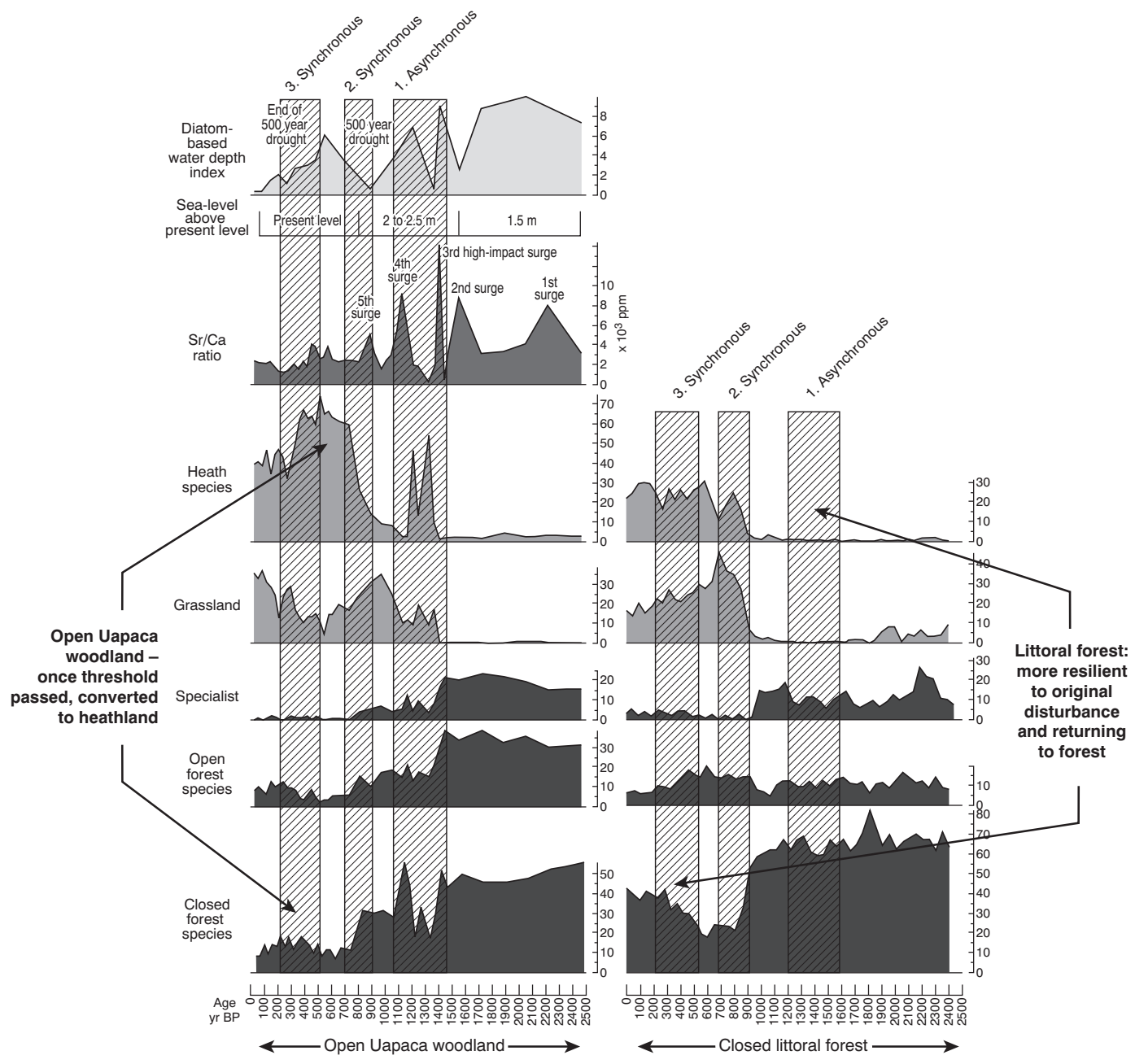

Fig. 2. Changes in selected taxa at the two habitat types: (a) Erica-heath (left hand panel) and (b) littoral forest fragment (right hand panel). Grey bands are periods of abiotic changes corresponding to vegetation shifts. Note the difference in species composition and timing of changes between the two sites (Redrawn from Virah-Swamy et al., 2009a).

this region) enabled the persistence of Symphonia; (iii) neither competition nor facilitation exerted any influence; and iv) both competition (Symphonia-Erica spp.) and facilitation (Symphonia-Myrica) were responsible for the persistence of the species at one site but not the other. Different models were fitted using a negative binomial likelihood function; maximum-likelihood parameter estimates were determined using a Nelder-Mead simplex algorithm (Bonsall and Hastings, 2004).

Results indicated that at both sites, the best model for describing the Symphonia dynamics was the competition model with Erica spp. In addition, when competition isoclines were plotted for the two sites it became apparent that at the site where Symphonia went locally extinct (Mandena), Erica and Symphonia coexisted at high abundances, but at low abundances, Erica outcompeted Symphonia. In contrast, at St. Luce, Symphonia and Erica spp. coexisted throughout the sequence. Mandena is an area with nutrient-poor soils, which are particularly deficient in phosphates and nitrogen. In contrast St. Luce has more nutrient-rich soils. It is therefore probable that at Mandena, plants that can grow in nitrogenpoor soils (e.g., Erica spp.) gained a competitive advantage during climate perturbations, expanded and reached maximum carrying capacity, driving Symphonia populations to local extinction. Thus it is the density of Erica that determines coexistence or competition effects at Mandena and this can result in local extinction during climatic perturbations. By contrast, at St Luce, the more nutrient-rich soils provided more resources for Symphonia during climatic perturbations. With higher Symphonia abundances, Symphonia exerted competitive effects on Erica spp. and persisted through the interval of climatic perturbation (Virah-Swamy et al., 2009c) (Fig. 3b).

By examining ecological processes responsible for persistence through time, this study raises important implications for conservation planning. It clearly indicates that population 
a)

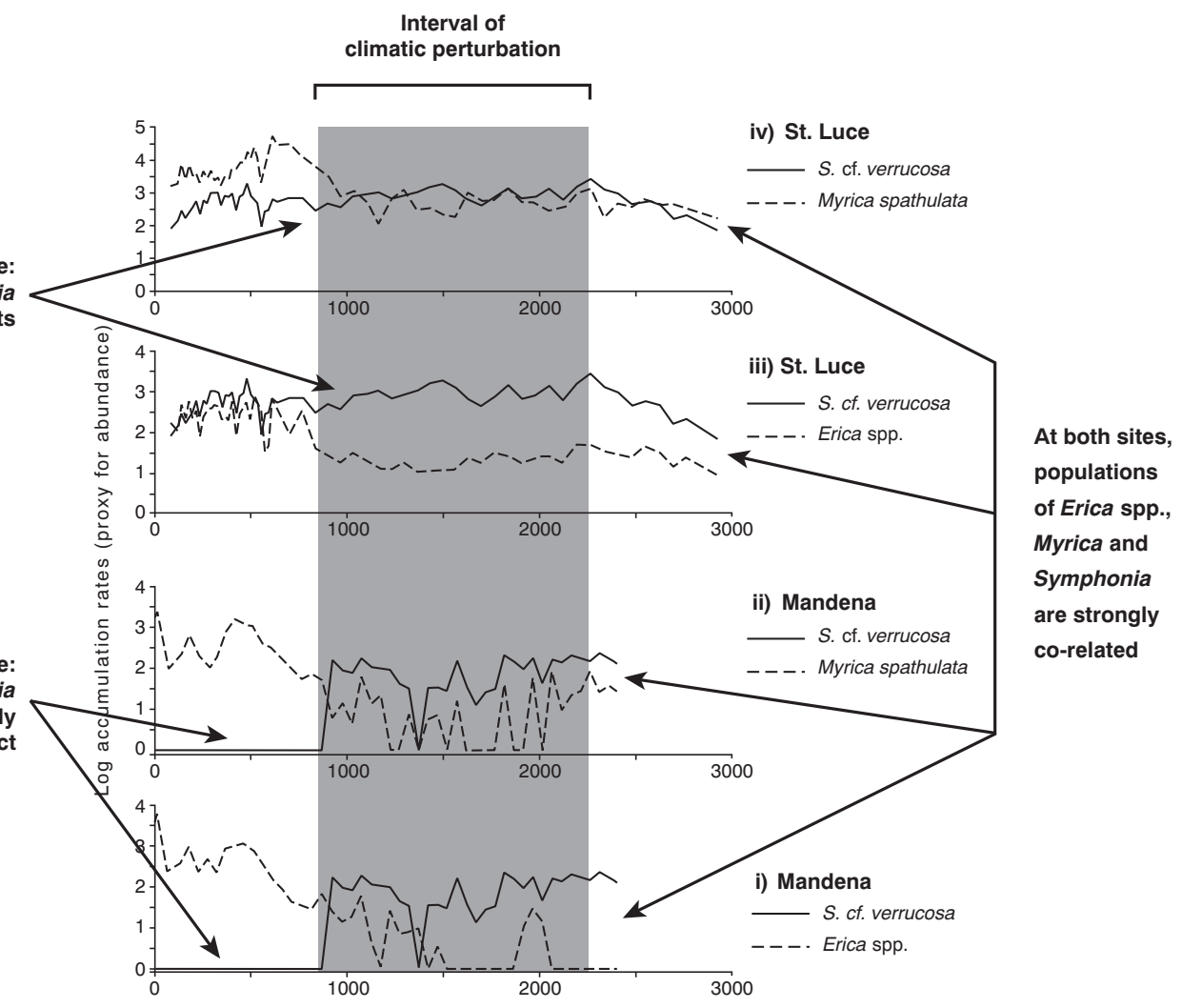

b)

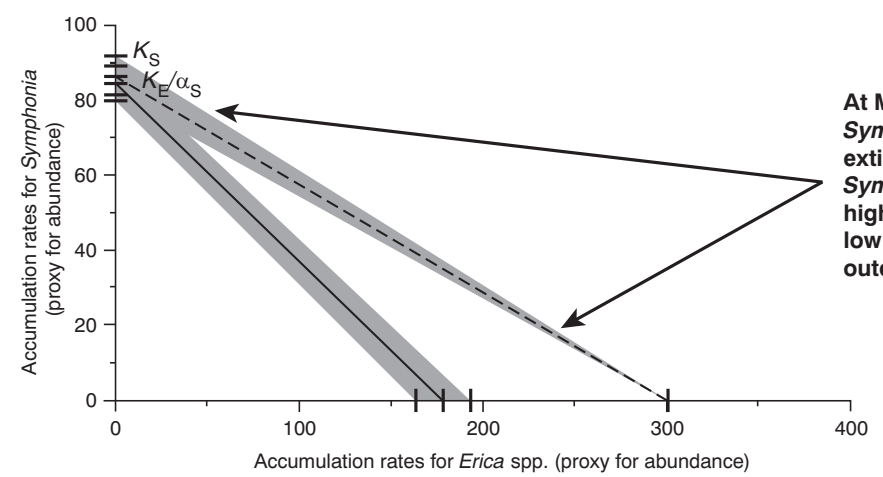

At Mandena (where

Symphonia went locally extinct), Erica and

Mandena site: Symphonia oes locally extinct ymphonia co-existed at high abundances, but at low abundances Erica outcompeted Symphonia

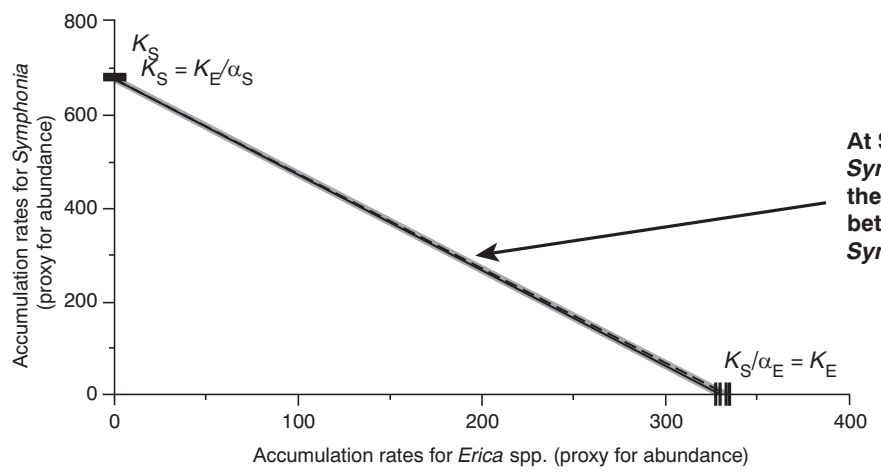

Competition isoclines:

- S. cf. verrucosa

- - - Erica spp.

At St. Luce, where Symphonia persisted,

there was co-existence

between Erica and

Symphonia

Fig. 3. (a) Symphonia dynamics in relation to Erica spp. and Myrica in two forest fragments: at fragment (Mandena M15) where it became extinct at 950 cal yr BP (i,ii) and another fragment (Saint Luce S9) where it persisted (iii,iv). Note that grey bands are periods of marine inundation between 2300 to 800 cal yr BP accompanied by climatic desiccation around 950 cal yr BP. (Redrawn from Virah-Swamy et al., 2009a) (b) Models describing Symphonia dynamics (Redrawn from Virah-Swamy et al., 2009c). 
abundance is more important for the persistence of Symphonia than the other factors considered (including facilitation by nitrogen fixers) and areas that are able to support higher numbers of individuals (due to abiotic factors such as better soil nutrients) enable partitioning of resources and competitive populations. With increasing fragmentation and reduction in sizes of populations, the most important regions for conservation prioritization in this region of Madagascar must be those areas of littoral forest situated on nutrient-rich soils, since during climate perturbations littoral forests located on poorer soils will probably not be able to support many of the region's important endemic taxa. By prioritizing conservation of littoral forest situated on nutrient-rich soils it will be possible to preserve the ecological processes necessary for its persistence during climatic perturbations.

\section{Restoration of ecological processes on a degraded landscape}

Throughout the 20 th century, a key conservation strategy has been maintenance and expansion of the global protected area network. Since the first national park was established in 1872, there are now over 100000 reserves covering more than 18 million $\mathrm{km}^{2}$ - over $12 \%$ of the Earth's land surface (WCMC, 2007). However, these reserves are spatially fixed, meaning that migration beyond reserves in response to climate change may not be possible for many species, particularly because reserves are also surrounded by highly human-dominated landscape matrix (Wittermeier et al., 2009). Furthermore, in order to migrate beyond reserves, many species will have to travel through novel ecosystems in anthropogenic landscapes. In such ecosystems, plant and animal communities are often influenced by people's preferences (e.g., cultivated and domesticated species) and alien or invasive species are also common. How can we then create conditions that will protect native species beyond reserves and in novel ecosystems? This may require a whole new approach to conservation, restoring ecological processes and enhancing the quality of landscape matrix surrounding reserves.

The first approach is to restore ecological processes to these degraded landscapes. This requires knowledge of what was there before degradation and the processes that were important for ecosystem function.

Currently in conservation practice, a movement is gaining increasing support is one that proposes to restore ecological processes in degraded landscapes through the re-introduction of large herbivores as "ecosystem engineers" (Vera, 1997, 2000) Vera (2000), for example, argues that to achieve functionality in an ecosystem it is necessary to restore the trophic structure, namely in the form of large herbivores that were widespread upon the landscape before their numbers were greatly reduced through hunting and removal for agricultural activities. In the case of European landscapes, Vera (1997,
2000) suggests that the animals to be reintroduced should be those apparent on the European landscape between $~ 10000$ $8000 \mathrm{yr} \mathrm{BP}$ and in North America (Donlan et al., 2005, 2006) and Northern Russia (Zimov, 2005) it is suggested that the animals to be reintroduced should be those present during the Pleistocene ( $>10000 \mathrm{yr} \mathrm{BP})$. Through such reintroductions, it is suggested that these large herbivores will improve ecosystem function through nutrient cycling, seeddispersal, increased biomass and increased diversity (Vera 1997, 2000; Donlan et al., 2005, 2006; Zimov, 2005). This approach of re-introducing large herbivores is already occurring at sites in the Netherlands, parts of North America (Rist et al., 2007) and the Northern Siberian region of Yakutia (Zimov, 2005) Preliminary results indicate a large increase in biodiversity over the past 30 years at Oostvaardesplassen in the Netherlands as a result of re-introducing heck cattle, konic ponies and red deer (Vera, 2009). This approach, however, is not without its critics (e.g., Rubenstein et al., 2006), not least from the paleoecological community (Mitchell, 2005; Soepboer and Lotter, 2009; Whitehouse and Smith, 2010). Understanding the relationship between past herbivore densities and their role as "ecosystem engineers" is an important future research challenge for long-term ecology.

A second approach for restoration of ecological processes in degraded landscapes may be to learn from the legacy of past human activities. Many of the landscapes in so-called biodiversity hotspots have a long history of human habitation and have been under some form of cultivation in the past (Willis et al., 2004). Past cultivation techniques included planting of trees along with crops in agroforestry systems (Heckenberger et al., 2007), and soil-management strategies (Bhagwat et al., 2008). For example, the ancient Maya manipulated and cultivated the landscape of the Yalahau region in the northeast corner of the Yucatan Peninsula in Mexico by using algae from wetlands to enrich upland garden plots, and by cultivating trees within their communities (Fedick and Morrison, 2004). Similarly, there is substantial evidence to indicate that fertile Terra Preta soils were developed by preColumbian native populations in central Amazonia through the addition of large amounts of charred residues, organic waste, excrement and bones (Glaser, 2007). Terra Preta soils also occur in other regions of South America including Ecuador and Peru, in Western Africa (Benin, Liberia) and in the savannas of South Africa (Willis et al., 2004). These soils, many created over 2000 years ago, contain 70 times more charcoal than surrounding soils and have greatly enhanced fertility due to high levels of soil organic matter and nutrients such as nitrogen, phosphorus, potassium, and calcium in a landscape of otherwise infertile soils. Terra Preta soils occur in small patches averaging 20 ha, but 350 ha sites have also been reported (Glaser, 2007). Field experiments to re-create contemporary Terra Preta in Amazonia with charcoal additions between $5-10 \mathrm{Mg} \mathrm{ha}^{-1}$ has increased crops yields up to $220 \%$ (Glaser et al., 2006). Interestingly in these examples, it is humans who are creating conditions 
necessary for increased biodiversity, indicating that ecological processes facilitated by past human management can also contribute to enhancing biodiversity.

\section{Identification of regions important for evolutionary processes}

Many of the examples given above illustrate questions related to processes responsible for maintaining diversity on ecological timescales. Another important question is how do we conserve processes responsible for genetic diversity and which is manifest on evolutionary timescales? Conservation of evolutionary processes is essential to maintain the ability of organisms to continue to adapt and evolve to new circumstances (Mace and Purvis, 2008). Although it is impossible to predict the future course of evolution, in order to conserve evolutionary processes, it is thus important to conserve regions that contain high genetic diversity and species/areas that are phylogenetically distinct (Issac et al., 2007). Paleoecological records, in combination with molecular phylogenies, have an important role to play in the identification of both of these factors.

Many studies now indicate that regions of greatest genetic diversity and genetically distinctive populations are those where plants and animals persisted in cold-stage refugia during intervals of climatic perturbations including the Pleistocene ice-ages (e.g., Hewitt, 2000; Douglas et al., 2006). Often these populations are at the trailing edge of the current species distribution and represent relict populations of a former distribution (Hampe and Petit, 2005). It is only through knowledge of their past distribution in refugia during the Pleistocene ice-ages (e.g., Willis et al., 2004; Bhagwat and Willis, 2008; Binney et al., 2009) that a detailed understanding of the spatial extent (and often patchy distribution) of genetic diversity can be appreciated (Petit et al., 2008). It also interesting to note that several studies now indicate that there is often no positive correlation between current species diversity and genetic diversity; the former tending to be associated with extant suitable habitats (e.g., soil type, moisture availability etc.) and the latter with location of glacial refugia and routes of postglacial colonization (e.g., Puşcaş et al., 2008).

Another consideration for conservation of evolutionary process is the location of "warm-stage" refugia, regions of persistence during interglacial periods. Given future climatic conditions, location of such refugia may be more important to ensure the future persistence and genetic diversity of cool temperate species including many endemic alpine and arctic taxa. An important time-interval to examine refugia for these species is the mid-Holocene climatic optimum between 8000-6000 cal yr BP when, for example, summers in Northern and Central Europe were $\sim 2-2.5^{\circ} \mathrm{C}$ and winters 1$1.5^{\circ} \mathrm{C}$ warmer than today (Birks, 1988,2008 ). Clear spatial differences are apparent in the distribution of many arctic and alpine species during this interval (Birks and Willis, 2008) and identification of pockets of so-called "cryptic" refugia.

So how can such information on cold and warm-stage refugia be incorporated into conservation management and planning? In a recent attempt to identify important areas for conservation of ecological processes in Australia, locations of refugia during previous intervals of aridity were incorporated into the spatial planning framework in order to determine regions for conservation (Klein et al., 2009). The interval of aridity being examined in this study occurred within the last few dacades but Klein et al. (2009) argued that these areas provide the most probable regions of persistence in future intervals of aridity and therefore represent important regions for conservation. A similar approach could be applied to many regions of the world using palaeoecological records of past distributions. Such an approach, predominantly focused on preserving areas important for species persistence in the future and on maintaining ecological processes necessary for this persistence, it also likely to preserve longevity of species/communities and thus evolutionary processes.

\section{Conclusions}

Many of the questions regarded as being important to the conservation of biological diversity require an understanding of the dynamic processes of species and their interactions with their environment (Sutherland et al., 2009). But amongst the majority of conservation organisations there is still a lack of appreciation of the relevance of ecological processes to conservation planning and there still are few methodologies available to incorporate them into strategic conservation planning (see however Pressey et al., 2007; Klein et al., 2009; Edwards et al., 2010). In addition, datasets recording ecological processes spanning timescales $>50$ years are absent from all such methods.

In the next decade with increased biotic/abiotic changes occurring, it is imperative that ecological and evolutionary processes are at the forefront of conservation planning rather than as an after-thought (Pressey et al., 2007; Mace and Purvis, 2008). Throughout this paper, we demonstrate that palaeoecological data are not just descriptive records detailing past change, but provide information on ecological and evolutionary processes that are highly relevant to management of present-day ecosystems including information on baselines, resilience and persistence, and identifying regions with greatest evolutionary potential. Such records provide an essential test of predictions and assumptions of ecological processes that are directly relevant to conservation management strategies. But a future research agenda must also develop an understanding of ecological processes "beyond the reserves" and for the management of "novel ecosystems" since this is where much of our biodiversity conservation will need to take place. 
So why are long-term ecological data not routinely incorporated into conservation planning for ecological processes? We suggest that there are currently a number of barriers, not least in the ability for presentation and accessibility of longterm ecological data to non-specialists. New tools for extraction, analysis and presentation of paleoecological data are needed which present the data in a format that is usable by non-specialists (e.g., Binney et al., 2009). There also needs to be far greater dialogue between the two communities in order to develop a clearer understanding of important questions. This should then lead to more focused paleoecological datasets that provide records on temporal scales and in research regions that are of relevance to conservationists (Froyd and Willis, 2008). Finally, we argue that the time is ripe for the development of a strategic conservation planning tool that routinely incorporates long-term ecological data in order to determine the best regions for conservation of ecological and evolutionary processes through time.

Acknowledgements. We thank PAGES for funding to attend the 3rd Open Science Meeting in Corvallis, Oregon, USA; Ailsa Allen for preparing figures, John Birks for comments on this manuscript and members of Long-term Ecology Laboratory, Oxford for stimulating discussion.

Edited by: C. Whitlock

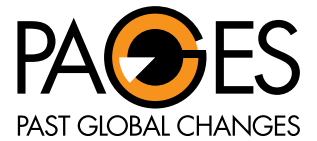

The publication of this article was sponsored by PAGES.

\section{References}

Bennett, A. F., Haslem, A., Cheal, D. C., Clarke, M. F., Jones, R. N., Koehn, J. D., Lake, P. S., Lumsden, L. F., Lunt, I. D., Mackey, B. G., Mac Nally, R., Menkhorst, P. W., New, T. R., Newell, G. R., O’Hara, T., Quinn, G. P., Radford, J. Q., Robinson, D., Watson, J. E. M., and Yen, A. L.: Ecological processes: A key element in strategies for nature conservation, Ecological Management and Restoration, 10(3), 192-199, 2009.

Bhagwat, S. A. and Willis, K. J.: Species persistence in northerly glacial refugia of Europe: a matter of chance or biogeographical traits? J. Biogeogr., 35, 464-482, 2008.

Bhagwat, S. A., Willis, K. J., Birks, H. J. B., and Whittaker, R. J.: Agroforestry: a refuge for tropical biodiversity?, Trends. Ecol. Evol., 23, 261-267, 2008.

Binney, H. A., Willis, K. J., Edwards, M. E., Bhagwat, S. A., Anderson, P. M., Andreev, A. A., Blaauw, M., Damblon, F., Haesaerts, P., Kienast, F., Kremenetski, K. V., Krivonogov, S. K., Lozhkin, A. V., MacDonald, G. M., Novenko, E. Y., Oksanen, P., Sapelko, T. V., Valiranta, M., and Vazhenina, L.: The distribution of late-Quaternary woody taxa in northern Eurasia: evidence from a new macrofossil database, Quaternary Sci. Rev, 28, 2445-2464, 2009.

Birks, H. J. B.: Long-term change in the British uplands, in: Ecological Change in the Uplands, edited by: Usher, M. B. and
Thompson, D. B. A., British Ecological Society Symposium, 7, Blackwell Scientific Publications, Oxford, 37-56, 1988.

Birks, H. J. B.: Holocene climate research - progress, paradigms, and problems, in: Natural Climate Variability and Global Warming: a Holocene Perspective, edited by: Battarbee, R. W. and Binney, H., Wiley-Blackwell, Chichester, 7-57, 2008.

Birks, H. J. B. and Willis, K. J.: Alpines, trees, and refugia in Europe, Plant Ecol. Diversity, 1, 147-160, 2008.

Boitani, L., Cowling, R. M., Dublin, H. T., Mace, G. M., Parrish, J., Possingham, H. P., Pressey, R. L., Rondinini, C., and Wilson, K. A.: Change the IUCN protected area categories to reflect biodiversity outcomes, PLoS Biology, 6, 436-438, 2008.

Bond, W. J. and Parr, C. L.: Beyond the forest edge: Ecology, diversity and conservation of the grassy biomes, Biol. Conserv., doi:10.1016/j.biocon.2009.12.012, in press, 2010.

Bond, W. J., Silander, J. A., Ranaivonasy, J., and Ratsirarson, J.: The antiquity of Madagascar's grasslands and the rise of C-4 grassy biomes, J. Biogeogr., 35, 1743-1758, 2008.

Bonsall, M. B. and Hastings, A.: Demographic and environmental stochasticity in predator-prey metapopulation dynamics, J. Anim. Ecol., 73, 1043-1055, 2004.

Brown, A. F., Stillman, R. A., and Gibbons, D. W.: Use of Breeding Bird Atlas Data to Identify Important Bird Areas - a Northern England Case-Study, Bird Study, 42, 132-143, 1995.

Carrion, J. S., Munuera, M., Dupre, M., and Andrade, A.: Abrupt vegetation changes in the Segura Mountains of southern Spain throughout the Holocene, J. Ecol., 89, 783-797, 2001.

CBD, 2010: Biodiversity Target, www.cbd.int/2010-target, last access: March 2010.

Dearing, J. A.: Landscape change and resilience theory: a palaeoenvironmental assessment from Yunnan, SW China, Holocene, 18 , 117-127, 2008.

Donlan, C. J., Berger, J., Bock, C. E., Bock, J. H., Burney, D. A., Estes, J. A., Foreman, D., Martin, P. S., Roemer, G. W., Smith, F. A., Soule, M. E., and Greene, H. W.: Pleistocene rewilding: An optimistic agenda for twenty-first century conservation, Am. Nat., 168, 660-681, 2006.

Donlan, J., Berger, J., Bock, C. E., Bock, J. H., Burney, D. A., Estes, J. A., Foreman, D., Martin, P. S., Roemer, G. W., Smith, F. A., Soule, M. E., and Greene, H. W., Re-wilding North America, Nature, 436, 913-914, 2005.

Douglas, M. E., Douglas, M. R., Schuett, G. W., and Porras, L. W.: Evolution of rattlesnakes (Viperidae; Crotalus) in the warm deserts of western North America shaped by Neogene vicariance and Quaternary climate change, Mol. Ecol., 15, 3353-3374, 2006.

Dudley, N.: Guidelines for Applying Protected Area Management Categories, IUCN, Gland, Switzerland, 2008.

Edwards, H. J., Elliott, I. A., Pressey, R. L., and Mumby, P. J.: Incorporating ontogenetic dispersal, ecological processes and conservation zoning into reserve design, Biol. Conserv., 143, 457470, 2010.

Fedick, S. L. and Morrison, B. A.: Ancient use and manipulation of landscape in the Yalahau region of the northern Maya lowlands, Agr. Hum. Values, 21, 207-219, 2004.

Figueroa-Rangel, B. L., Willis, K. J., and Olvera-Vargas, M.: 4200 years of pine-dominated upland forest dynamics in west-central Mexico: Human or natural legacy?, Ecology, 89, 1893-1907, 2008. 
Folke, C., Carpenter, S., Walker, B., Scheffer, M., Elmqvist, T., Gunderson, L., and Holling, C. S.: Regime shifts, resilience, and biodiversity in ecosystem management, Annu. Rev. Ecol. Evol. S, 35, 557-581, 2004.

Foster, D. R. and Motzkin, G.: Interpreting and conserving the openland habitats of coastal New England: insights from landscape history, Forest. Ecol. Manag., 185, 127-150, 2003.

Froyd, C. A. and Willis, K. J.: Emerging issues in biodiversity and conservation management: The need for a palaeoecological perspective, Quaternary Sci. Rev., 27, 1723-1732, 2008.

Glaser, B.: Prehistorically modified soils of central Amazonia: a model for sustainable agriculture in the twenty-first century, Philos. T. R. Soc. B., 362, 187-196, 2007.

Goodman S. M. and Benstead, J. P.: The natural history of Madagascar, Chicago, IL: University of Chicago Press, 2003.

Hampe, A. and Petit, R. J.: Conserving biodiversity under climate change: the rear edge matters, Ecol. Lett., 8, 461-467, 2005.

Hecker, S. J., Cho, I. S., Glinka, T. W., Zhang, Z. J., Price, M. E., Lee, V. J., Christensen, B. G., Boggs, A., Chamberland, S., Malouin, F., Parr, T. R., Annamalai, T., Blais, J., Bond, E. L., Case, L., Chan, C., Crase, J., Frith, R., Griffith, D., Harford, L., Liu, N., Ludwikow, M., Mathias, K., Rea, D., and Williams, R.: Discovery of MC-02,331, a new cephalosporin exhibiting potent activity against methicillin-resistant Staphylococcus aureus, J. Antibiot., 51, 722-734, 1998.

Hewitt, G.: The genetic legacy of the Quaternary ice ages, Nature, 405, 907-913, 2000.

Hobbs, R. J., Arico, S., Aronson, J., Baron, J. S., Bridgewater, P., Cramer, V. A., Epstein, P. R., Ewel, J. J., Klink, C. A., Lugo, A. E., Norton, D., Ojima, D., Richardson, D. M., Sanderson, E. W., Valladares, F., Vila, M., Zamora, R., and Zobel, M.: Novel ecosystems: theoretical and management aspects of the new ecological world order, Global Ecol. Biogeogr., 15, 1-7, 2006.

Isaac, N. J., Turvey, S. T., Collen, B., Waterman, C., and Baillie, J. E.: Mammals on the EDGE: conservation priorities based on threat and phylogeny, PLoS ONE, 2(3), e296, doi:10.1371/journal.pone.0000296, 2007.

Jackson, S. T. and Hobbs, R. J.: Ecological Restoration in the Light of Ecological History, Science, 325, 567-569, 2009.

Jenkins, C. N. and Joppa, L.: Expansion of the global terrestrial protected area system, Biol. Conserv., 142, 2166-2174, 2009.

Klein, C. J., Wilson, K. A., Watts, M., Stein, J., Carwardine, J., Mackey, B., and Possingham, H. P.: Spatial conservation prioritization inclusive of wilderness quality: A case study of Australia's biodiversity, Biol. Conserv., 142, 1282-1290, 2009.

List, R., Ceballos, G., Curtin, C., Gogan, P. J. P., Pacheco, J., and Truett, J.: Historic distribution and challenges to bison recovery in the northern Chihuahuan Desert, Conserv. Biol., 21, 14871494, 2007.

Mace, G. M., Balmford, A., and Ginsberg, J.: Conservation in a changing world, Cambridge University Press, Cambridge, 309 pp., 1998.

Mace, G. M. and Purvis, A.: Evolutionary biology and practical conservation: bridging a widening gap, Mol. Ecol., 17, 9-19, 2008.

Marlon J. R., Bartlein, P. J., Carcaillet, C., Gavin, D. G., Harrison, S. P., Higuera, P. E., Joos, F., Power, M. J., and Prentice, I. C.: Climate and human influences on global biomass burning over the past two millennia, Nature Geoscience 1, 697-702, 2008.
Maxwell, A. L.: Fire regimes in north-eastern Cambodian monsoonal forests, with a 9300-year sediment charcoal record, J. Biogeogr., 31, 225-239, 2004.

Mitchell, F. J. G.: How open were European primeval forests?, Hypothesis testing using palaeoecological data, J. Ecol., 93, 168177, 2005.

Myers, N., Mittermeier, R. A., Mittermeier, C. G., da Fonseca, G. A. B., and Kent, J.: Biodiversity hotspots for conservation priorities, Nature, 403, 853-858, 2000

Olson, D. M. and Dinerstein, E.: The global 200: A representation approach to conserving the Earth's most biologically valuable ecoregions, Conserv. Biol., 12, 502-515, 1998.

Parr, C. L., Bond, W. J., and Robertson, H. G.: A preliminary study of the effect of fire on ants (Formicidae) in a South African savanna, Afr. Entomol., 10, 101-111, 2002.

Petit, R. J., Hu, F. S., and Dick, C. W.: Forests of the past: A window to future changes, Science, 320, 1450-1452, 2008.

Pressey, R. L., Cabeza, M., Watts, M. E., Cowling, R. M., and Wilson, K. A.: Conservation planning in a changing world, Trends Ecol. Evol., 22, 583-592, 2007.

Puscas, M., Taberlet, P., and Choler, P.: No positive correlation between species and genetic diversity in European alpine grasslands dominated by Carex curvula, Divers. Distrib., 14, 852-861, 2008.

Rubenstein, D. R., Rubenstein, D. I., Sherman, P. W., and Gavin, T. A.: Pleistocene park: Does re-wilding North America represent sound conservation for the 21 st century?, Biol. Conserv., 132, 232-238, 2006.

Scheffer, M., Bascompte, J., Brock, W. A., Brovkin, V., Carpenter S. R., Dakos, V., Held, H., van Nes, E. H., Rietkerk, M., and Sugihara, G.: Early-warning signals for critical transitions, Nature, 461, 53-59, 2009.

Soepboer, W. and Lotter, A. F.: Estimating past vegetation openness using pollen-vegetation relationships: A modelling approach, Rev. Palaeobot. Palyno., 153, 102-107, 2009.

Sutherland, W. J., Adams, W. M., Aronson, R. B., Aveling, R., Blackburn, T. M., Broad, S., Ceballos, G., Cote, I. M., Cowling, R. M., Da Fonseca, G. A. B., Dinerstein, E., Ferraro, P. J., Fleishman, E., Gascon, C., Hunter, M., Hutton, J., Kareiva, P., Kuria, A., MacDonald, D. W., MacKinnon, K., Madgwick, F. J., Mascia, M. B., McNeely, J., Milner-Gulland, E. J., Moon, S., Morley, C. G., Nelson, S., Osborn, D., Pai, M., Parsons, E. C. M., Peck, L. S., Possingham, H., Prior, S. V., Pullin, A. S., Rands, M. R. W., Ranganathan, J., Redford, K. H., Rodriguez, J. P., Seymour, F., Sobel, J., Sodhi, N. S., Stott, A., Vance-Borland, K., and Watkinson, A. R.: One Hundred Questions of Importance to the Conservation of Global Biological Diversity, Conserv. Biol., 23, 557-567, 2009.

Vera, F. W. M.: Metaforen voor de Wildernis: eik, hazelaar, rund en paard, Wageningen Agricultural University, 1997.

Vera, F. W. M.: Grazing Ecology and Forest History, CABI Publishing, Wallingford, UK, 2000.

Virah-Sawmy, M., Gillson, L., and Willis, K. J.: How does spatial heterogeneity influence resilience to climatic changes?, Ecological dynamics in southeast Madagascar, Ecol. Monogr., 79, 557574, 2009a.

Virah-Sawmy, M., Willis, K. J., and Gillson, L.: Threshold response of Madagascar's littoral forest to sea-level rise, Global Ecol. Biogeogr., 18, 98-110, 2009b 
Virah-Sawmy, M., Bonsall, M. B., and Willis, K. J.: "Tales of Symphonia": extinction dynamics in response to past climate change in Madagascan rainforests, Biol. Letters, 5, 821-825, 2009c.

WDPA: World Database on Protected Areas, www.wdpa.org, last access: June 2010.

West, J. M. and Salm, R. V.: Resistance and resilience to coral bleaching: Implications for coral reef conservation and management, Conserv. Biol., 17, 956-967, 2003.

Whitehouse, N. J. and Smith, D.: How fragmented was the British Holocene wildwood? Perspectives on the "Vera" grazing debate from the fossil beetle record, Quaternary Sci. Rev., 29, 539-553, 2010.

Willis, K. J., Araujo, M. B., Bennett, K. D., Figueroa-Rangel, B., Froyd, C. A., and Myers, N.: How can a knowledge of the past help to conserve the future? Biodiversity conservation and the relevance of long-term ecological studies, Philos. T. R. Soc. B., 362, 175-186, 2007.
Willis, K. J., Bailey R. M., Bhagwat S. A., and Birks H. J. B.: Biodiversity baselines, thresholds and resilience: testing predictions and assumptions using palaeoecological data, Trends in Ecology and Evolution, 25(10), 583-591, 2010.

Willis, K. J. and Birks, H. J. B.: What is Natural? The need for a long-term perspective in biodiversity conservation, Science, 314 , 1261-1265, 2006.

Willis, K. J., Gillson, L., and Brncic, T. M.: How "virgin" is virgin rainforest?, Science, 304, 402-403, 2004.

Willis, K. J., Gillson, L., and Virah-Sawmy, M.: Nature or nurture: the ambiguity of C-4 grasslands in Madagascar, J. Biogeogr., 35, 1741-1742, 2008.

Wittemyer, G., Elsen, P., Bean, W. T., Burton, A. C. O., and Brashares, J. S.: Accelerated human population growth at protected area edges, Science, 321, 123-126, 2008.

Zimov, S. A.: Pleistocene park: Return of the mammoth's ecosystem, Science, 308, 796-798, 2005. 